\title{
Genotyping of Coxiella burnetii in sheep and goat abortion samples
}

\author{
Dimosthenis Chochlakis ${ }^{1 \dagger}$, Ana Sofia Santos ${ }^{2 \dagger}$, Nektarios D. Giadinis ${ }^{3}$, Dimitrios Papadopoulos ${ }^{4}$, Leonidas Boubaris ${ }^{1}$, \\ Emmanouil Kalaitzakis ${ }^{3}$, Anna Psaroulaki ${ }^{1,5^{*}}$, Spyridon K. Kritas ${ }^{4}$ and Evanthia I. Petridou ${ }^{4}$
}

\begin{abstract}
Background: Q fever, caused by Coxiella burnetii, is a zoonosis that presents a worldwide distribution and affects both humans and animals. The route of dispersal of the pathogen by ruminants into the environment usually involves stages of abortion and parturition, nevertheless the agent can, also, be detected in other animal samples. Therefore it is considered as important in terms of proper diagnosis, as well as, for epidemiology and surveillance purposes, to genotype the pathogen. The aim of the current study was to investigate the presence of different genotypes of the agent in animals that had suffered from abortion during a two-year survey in Greece.

Results: Sixty nine tissue samples (37 stomach contents, 11 liver samples, 21 cotyledons) were collected from 59 abortion cases in sheep $(N=45)$ and goats $(N=14)$ from 65 farms at eight different areas of Greece. Samples were screened by qPCR and positive ones were further genotyped using a 10-locus multiple loci ( $m s$ 1, 3, 7, 12, 20, 21, 22, 26,30 and 36 ) variable number of tandem repeat analysis (MLVA) method.

Three genotypes were identified in sheep (A, B, C). Samples representing each of the obtained MLVA profile were further used for MST genotyping. Ten spacers (Cox 2, 5, 6, 18, 20, 22, 37, 51, 56 and 57) were amplified. A close relatedness among the identified MLVA genotypes was confirmed since they all belonged to MST group 32.

Conclusions: The current study introduces into the aspect of genotyping of C. burnetii in Greece. Further studies are needed to explore the presence of more genotypes, to associate the genotypes circulating in the animal and tick population with those causing human disease in order to further expand on the epidemiological aspects of the pathogen.
\end{abstract}

Keywords: Small ruminants, Abortion, Coxiella burnetii, MLVA, MST

\section{Background}

Q fever, caused by the pathogen Coxiella burnetii, is a zoonosis with a worldwide distribution [1]. The presence of the pathogen has been reported in a great variety of animals including wild and domestic mammals (goats, sheep, cows, buffaloes and potentially other dairy ruminants, more rarely dogs and cats). The agent has, also,

\footnotetext{
* Correspondence: psaroulaki@uoc.gr

${ }^{\dagger}$ Dimosthenis Chochlakis and Ana Sofia Santos contributed equally to this work.

'Department of Clinical Microbiology and Microbial Pathogenesis, School of Medicine, University of Crete, Voutes-Staurakia, 71110 Heraklion, Crete, Greece

${ }^{5}$ Unit of Zoonoses, Laboratory of Clinical Microbiology and Microbial Pathogenesis, Faculty of Medicine, University of Crete, P.O. Box: 1393, 71110 Heraklion, Crete, Greece

Full list of author information is available at the end of the article
}

been detected in ticks, although there is still controversy on whether these arthropods can act both as reservoirs for maintaining $C$. burnetii in nature and as vectors for transmitting it to humans.

Domestic ruminants (particularly sheep, goats, and cattle) are often asymptomatic carriers of the pathogen or express mild clinical manifestations associated with abortion, stillbirth, placentitis, endometritis and infertility [2-4]. These animals, either ill or healthy (carriers), are considered the major source of infection to humans [1]. In fact, a vast number of bacteria can be shed by domestic ruminants through milk, faeces, vaginal secretions and mostly placenta and birth products. Coxiella burnetii spores are highly infectious and stable under environmental conditions and are easily dispersed by airflow, that is why the main route of infection is 
considered to be inhalation of contaminated aerosols or dust [5]. Spores can, also, be spread several kilometers away from the primary infection source through wind, raising the latter as a potential player for bacterial dispersal [6].

It is of great importance to be able to trace back the sources of infection and to characterize the strains of the pathogen present in certain areas, both for epidemiological and for public health reasons (for example, surveillance purposes and trace of $\mathrm{Q}$ fever outbreaks). The most up to date event that leads towards the necessity of tracing and surveying the source of infection was the outbreak that took place in the Netherlands (2007-2010). This event has drawn further attention on the study of the pathogen even in countries where a low prevalence of the disease was usually recorded, as was the case of the Netherlands until the outbreak episodes $[1,7]$. To achieve such a demanding goal, the most reliable way is to use molecular tools for the genotypic characterization of $C$. burnetii in order to evaluate the epidemiological link between the source of the outbreak and human and/or animal cases. The ultimate goal in any case is to establish control measures with respect to hosts involved in the life cycle of the pathogen in order to minimize or even just survey its dispersal.

A number of different molecular typing methods have been used to achieve the above mentioned goals including, restriction fragment length polymorphism (RFLP) in combination with pulse field gel electrophoresis (PFGE) $[8,9]$, multi-locus variable number of tandem repeats analysis (MLVA; more than 20 publications following the 1st one in 2006 [10]), multispacer sequence typing (MST) [11], and single nucleotide polymorphism (SNP) [12, 13]. Of the mentioned techniques, MLVA and MST have proved to be reliable, reproducible, and present a high discriminatory power. They do not require cultivation of the pathogen, which not only is it difficult to achieve but, also, obliges Biosafety Level (BSL) 3 facilities, while there is always the possibility of isolation failure due to contamination (especially in abortion samples). As far as MLVA is concerned, it is now considered as the reference method for a number of other pathogens: Mycobacterium tuberculosis [14], Bacillus anthracis [15], and Yersinia pestis [16]. MLVA is particularly useful in cases where there is a need for a deeper study of new genome sequences $[17,18]$.

In Greece, despite the fact that reporting of $Q$ fever should be mandatory, no more than 40 human cases are recorded annually at the Hellenic Center for Disease and Control, making its incidence possibly underestimated. Moreover, the absence of $C$. burnetii routine testing of animals of veterinary interest, leads to the conclusion that very few animal cases are recorded on an annual basis. A number of studies have been carried out in
Greece during the last 20 years in humans in order to document the prevalence of the disease, its potential complications, describe the difference in the kinetics of the antibodies between acute and chronic $\mathrm{Q}$ fever, identify possible proteins of the pathogen involved in the disease and their potential virulence, etc.; nevertheless, there is no information on the genotypic diversity of the pathogen circulating in the country (at the discussion section we comment further on the studies carried out in the country so far).

In the current study, C. burnetii DNA obtained from small ruminant abortion samples was genotyped. We introduce the use of MLVA and of MST in the study of the genetic diversity of the pathogen that is circulating in the country, as a first step to establish the link with potential sources of human infection.

\section{Methods \\ Sampling}

Samples were collected from 59 abortion episodes that occurred in sheep $(N=45)$ and goats $(N=11)$ from December 2014 to November 2016. The study enrolled 65 farms situated in middle, north, northeastern and northwestern Greece (Fig. 1). A total of 69 samples consisting of stomach content $(N=45)$, liver samples $(N=11)$ and cotyledons $(N=14)$, were obtained collected immediately after the abortion, packaged with ice and transported to the Farm Animal Clinic for examination.

\section{Molecular analysis}

DNA extraction was performed at the Clinic of Farm Animals, Faculty of Veterinary Medicine, School of Health Sciences, Aristotle University of Thessaloniki, using the QIAamp Tissue kit (QIAGEN Gmbh, Hilden, Germany). The concentration of extracted DNA was measured as the optical density at $260 \mathrm{~nm}$ using the Nanodrop 2000 photometer (Thermo Scientific). DNA samples were stored at $-20^{\circ} \mathrm{C}$ until further analysis. The initial qPCR screening of the samples and the MLVA genotyping were performed at the unit of Zoonoses of the Department of Clinical Microbiology and Microbial Pathogenesis (National Reference center for tick-borne pathogens), School of Medicine, University of Crete. The MST genotyping was carried out at the Center for Vectors and Infectious Disease Reserach, National Institute of Health Doutor Ricardo Jorge, Portugal.

\section{Real-time polymerase chain reaction (qPCR)}

To screen for the presence of $C$. burnetii DNA a qPCR was performed targeting the repeated sequence IS1111 [19]. The $20 \mu \mathrm{l}$ reaction consisted of mastermix (BioRad), $0.4 \mu \mathrm{M}$ of each primer, $0.2 \mu \mathrm{M}$ of probe and $2.5 \mu \mathrm{l}$ of DNA sample. Amplification was carried out in a CFX96 C1000 Real-time PCR (BioRad), under the following 


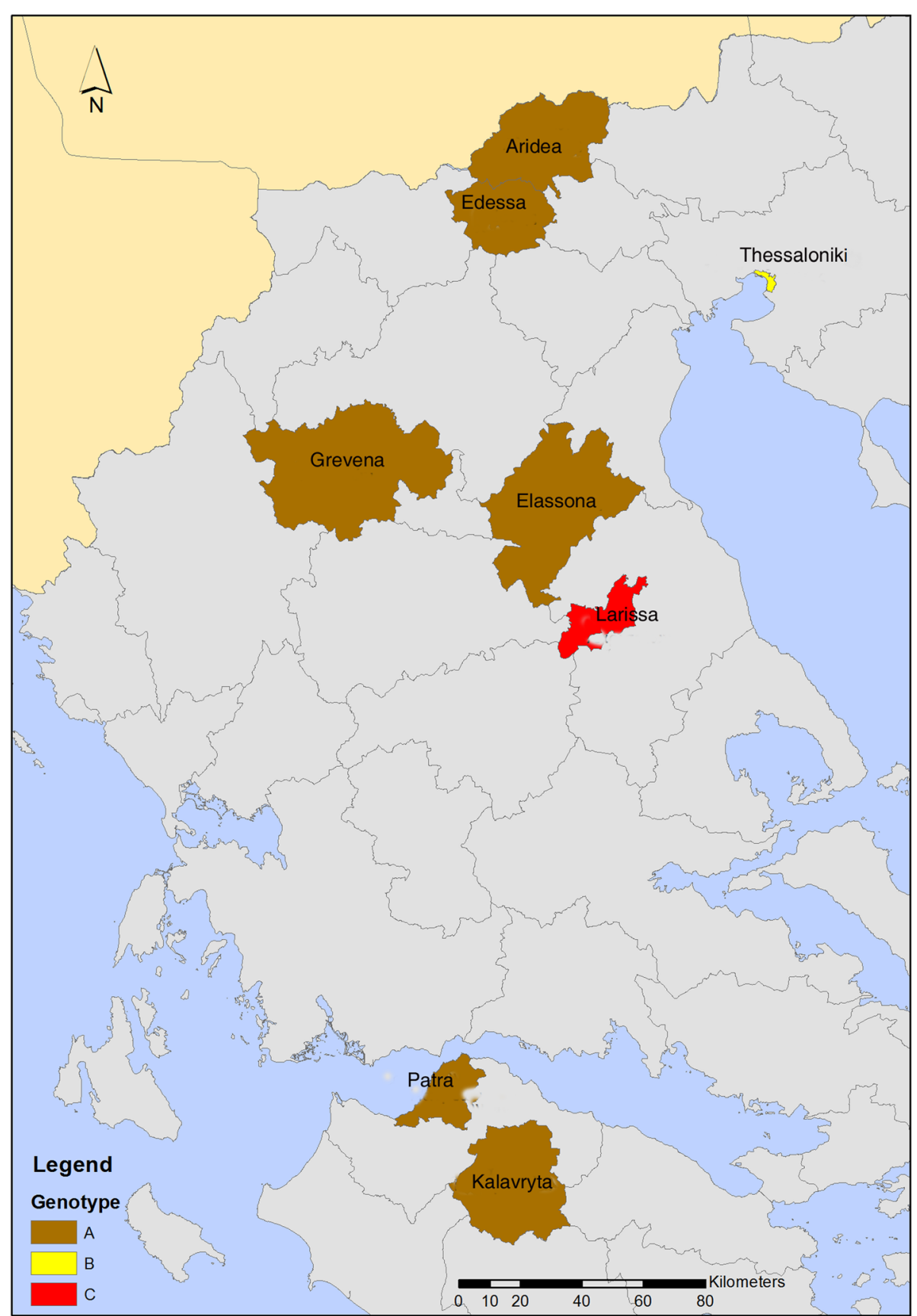

Fig. 1 Geographical distribution of the genotypes (A, B, C) detected in the animals (sheep) tested positive by qPCR

conditions: one cycle at $95^{\circ} \mathrm{C}$ for $180 \mathrm{~s}, 40$ cycles at $95^{\circ} \mathrm{C}$ for $10 \mathrm{~s}$ and $55^{\circ} \mathrm{C}$ for $30 \mathrm{~s}$. Results were generated with CFX Manager Software v. 1.6 (BioRad). Samples showing cycle threshold $(\mathrm{Ct})$ values of 31 or lower for C. burnetii IS1111 qPCR assays were considered positive, according to an already described procedure [20]. DNA extracted from a Nine Mile strain (RSA 493) strain, which is maintained in culture (Vero cells) at the laboratory, was used as a positive control and double distilled water was used as a negative one.

\section{Multiple-locus variable-number tandem repeat analysis (MLVA)}

All C. burnetii positive samples were further used for MLVA genotyping. Ten different loci ( $\mathrm{ms} \mathrm{1,} \mathrm{3,} \mathrm{7,} \mathrm{12,} \mathrm{20,}$ $21,22,26,30$ and 36) were selected for DNA amplification, as previously described [10, 21]. Nine Mile strain (RSA 493) for which the expected MLVA pattern is known, was used as a reference control strain to assist with the interpretation and the estimation of the number of repeat units. Following gel electrophoresis, the number 
of repeats in each marker was determined by extrapolating the sizes of the reference strain from those obtained from our samples. According to the established consensus, the genotype of the Nine Mile strain is now designated as 4-7-8-8-15-6-6-4-12-4 for markers $m s 01$, ms03, ms07, ms12, ms20, ms21, ms22, ms26, ms30 and ms36, respectively. Differences in PCR products were analysed using the Alpha View software v. 3 (Alpha Innotech). MLVA tools and databases of several organisms were accessed over the website http://mlva.u-psud.fr/mlvav4/ genotyping/view.php. This database was made available in 2014 aggregating mainly data published in 2006 by Arricau-Bouvery et al. ("C. burnetii 2007 Orsay" database), data provided by Kinga Sulyok, Miklós Gyuranecz and col., Institute for Veterinary Medical Research, Budapest, Hungary ("C. burnetii 2014" Hungary database) and data produced since 2007 by Jeroen Tilburg et al. ("C. burnetii 2014 Nijmegen" database).

\section{Multi-spacer sequence typing (MST)}

Samples representing each of the obtained MLVA profile were used for MST genotyping. In order to achieve that, ten different spacers (Cox 2, 5, 6, 18, 20, 22, 37, 51, 56 and 57) of the C. burnetii genome were amplified, as described elsewhere $[11,22]$. Conventional PCRs were performed in 50- $\mu$ l reaction using $1 \times$ FastStart Master Mix (Roche Diagnostics), containing $0.5 \mu \mathrm{M}$ of amplification primers and $5 \mu \mathrm{l}$ of DNA sample. After amplification purification and sequencing, the forward and reverse sequences generated for each of the 10 loci were aligned on the DNAStar sequence analysis software. The MST group was then identified using a web-based MST database (http://ifr48.timone.univ-mrs.fr/mst/coxiella_burnetii// mst/coxiella_burnetii/strains.html). In order to integrate the C. burnetii DNA detected, a phylogenetic analysis was performed using the MEGA v.7 software [23] using concatenated sequences of most of the known MST genotypes. The evolutionary distances were inferred using the Neighbor-Joining method (computing the Maximum Composite Likelihood method) and expressed in the number of base substitutions per site by pair wise comparison of 48 nucleotide sequences (Fig. 2). The eco-epidemiological context of MST genotypes, i.e. information on geographical distribution, occurrence and affected animal host, was compiled from the open-source MST database and from several published papers.

\section{Results}

Of the 69 samples tested, 11 (15.9\%) were positive by qPCR and were further genotyped by MLVA. All samples originated from sheep abortion cases that occurred in 11 farms located in eight different regions (Table 1 and Fig. 1). Attempts to genotype two samples with higher $\mathrm{Cq}$ values were unsuccessful probably due to the lower $C$. burnetii DNA content. Furthermore, we failed to amplify locus $m s 26$ despite repetitive attempts. Three different genotypes were detected in 11 samples: "A" was the most common and was detected in nine samples; "B" and "C" were detected in one sample each. Genotype B differed at the size of a single locus (ms22) only, compared to most prevalent genotype A, by a number of $33 \mathrm{bp}$, while genotype $\mathrm{C}$ differed at the size of three loci $(m s 22, m s 30$ and ms36) by a size of $66 \mathrm{bp}, 18 \mathrm{bp}$ and $45 \mathrm{bp}$ respectively, when compared to the most prevalence genotype A (Table 1). The dispersal of genotype A did not follow any particular pattern, since it was detected both in northern, central and in southern areas of the country. These genotypes represented unique MLVA profiles when compared to those deposited in open-access banks (http://mlva.u-psud.fr/MLVAnet/spip.php?rubrique50, http://microbesgenotyping.i2bc.paris-saclay.fr/databases/).

To complement the molecular analysis and to try to find a match with previous detected $C$. burnetii genotypes, one sample representing each of the MLVA profile was, also, used for MST typing. This is a less discriminatory method however, it is broadly used and has a standardized nomenclature allowing easy comparison of results among laboratories. The obtained results, confirmed the close relatedness among the MLVA genotypes $\mathrm{A}, \mathrm{B}, \mathrm{C}$ since they were all identified as belonging to MST group 32. The allele codes found were 3-5-1-6-5-4-5-12-3-2 for spacers Cox2-Cox5-Cox18Cox20-Cox22-Cox37-Cox51-Cox56-Cox57-Cox61. This MST genotype has been previously identified colonizing human cardiac valves in France and Germany, goat placenta in Austria (http://ifr48.timone.univ-mrs.fr/mst/coxiella_burnetii/strains.html) and sheep milk products in Tuscany, Italy [24]. The Neighbor-joining tree demostrating the placement of MST 32 (including the C. burnetii strain detected in this study) and the phylogenetic relationship with other genotypes, reinforce this zoonotic role (Fig. 2). MST 32 is placed in a tree branch (bootstrap of 70) that comprises several genotypes that particularly affect humans (60 samples) and small domestic ruminants (31 samples), and in a lesser extent cattle (4 samples) (Fig. 2 and Table 1). The data used to produce Fig. 2 are presented at Additional file 1: Table S1.

\section{Discussion}

In Greece, the notification of human Q fever cases is mandatory however under-reporting is one of the main limitations in disease assessment. There is, also, no continuous and reliable recording of the distribution of human and animal cases in the country thereafter, the identification of the source and route of infection remains largely unknown. More than 30 studies have been carried out during the past 20 years in Greece in an 


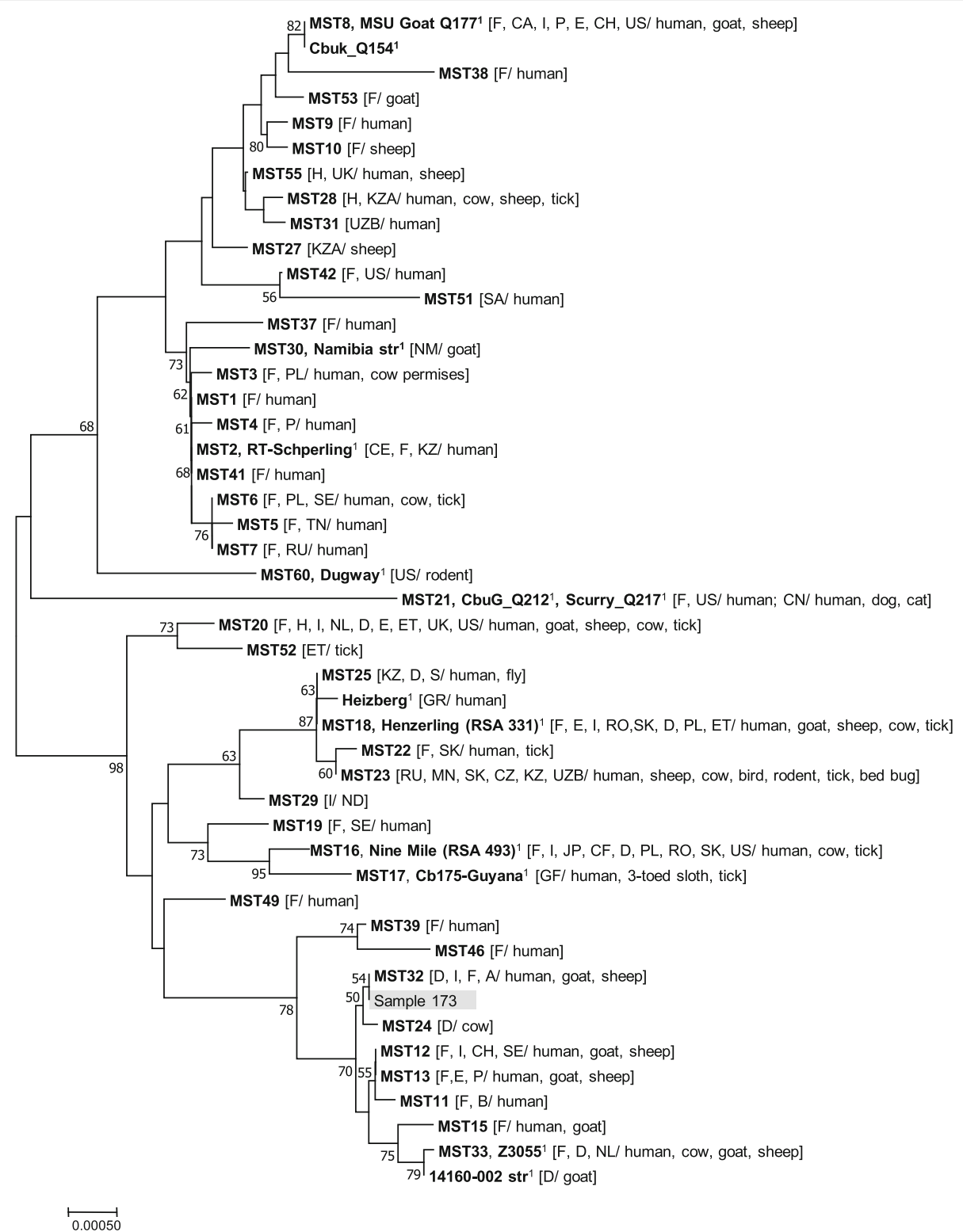

Fig. 2 The placement of the C. burnetii strain detected in this study (represented by sample 173, highlighted in grey) with the known MST genotypes. The analysis was performed using MEGA v.7 software (Kumar et al., 2016 [23]) using the Neighbor-joining method (Maximum Composite Likelihood method) with 1000 replicates. Bootstrap values $>50$ are shown. The scale bar represents the number of nucleotide substitutions per site. Host and geographic origin of C. burnetii genotypes are provided, according to open source databases and previous publications (listed in Additional file 1: Table S1). Country codes used: CE-Republic of Crimea; CF-Central African Republic; CH-Switzerland; CZ-Czech Republic; D-Germany; E-Spain; ET-Ethiopia; F-France; GF-French Guiana; GR-Greece; H-Hungary; I-Italy; JP-Japan; KZ-Kazakhstan; MN-Mongolia; NLNetherlands; NM-Namibia; P-Portugal; PL-Poland; RO-Romania; RU-Russia; S-Sweden; SA-Saudi Arabia; SE-Senegal; SK-Slovakia; TN- Tunisia; UK-United kingdom; UKR-Ukraine; US-United States; UZB-Uzbekistan. 'Reference strains: MSU Goat Q177 (Genbank accession number CP18150); Cbuk_Q154 (access no CP001020); Heizberg (access no CP014561); 14,160-002 str (access no CP014836); Namibia str (access no CP007555); Dugway (access no CP000733); CbuG_Q212 (access no CP001019); Scurry_Q217 (access no CP014565); Henzerling (RSA 331) (access no CP000890); Nine Mile (RSA 493) (access no AE016828);;Cb175-Guyana (access no HG825990); Z3055 (access no LK937696); RT-Schperling (access no CP014563)

attempt to expand the knowledge on C. burnetii; they have been focused on the pathogen isolation from humans [25] and the associated disease [26], its detection in ticks [27], on antibiotics resistance [28] and on proteomic analysis [29-31]. Despite the above, very few information is available regarding strain diversity. This study increases knowledge on the subject with the MLVA and MST-typing of nine C. burnetii positive samples obtained from different areas of Greece, deciphering its potential zoonotic role.

Overall, three MLVA genotypes (A, B and C) were detected in the current study. Genotype A was the most 
Table 1 Amplification of 10 loci from panel A as this has been established (http://mlva.u-psud.fr//MLVAnet/spip.php?rubrique50)

\begin{tabular}{|c|c|c|c|c|c|c|c|c|c|c|c|c|c|c|c|c|c|}
\hline \multirow[t]{3}{*}{ ID } & \multirow[t]{3}{*}{ Host } & \multirow[t]{3}{*}{ Source } & \multirow[t]{3}{*}{ Location } & \multirow[t]{3}{*}{ Year } & \multirow[t]{3}{*}{$\mathrm{Ct}$} & \multicolumn{11}{|l|}{ MLVA } & \multirow{3}{*}{$\begin{array}{l}\text { MST } \\
\text { type }\end{array}$} \\
\hline & & & & & & \multicolumn{10}{|c|}{ Loci targeted } & \multirow[t]{2}{*}{ Type } & \\
\hline & & & & & & ms01 & ms03 & ms07 & $m s 12$ & $m s 20$ & ms21 & ms22 & $m s 26$ & $m s 30$ & $m s 36$ & & \\
\hline 27 & Sheep & Stomach content & Grevena & 2015 & 27.1 & 0 & 0 & 0 & -2 & 3 & 0 & -7 & N/A & 0 & 3 & $A$ & \\
\hline $45 / 2$ & Sheep & Stomach content & Elassona & 2015 & 28.6 & 0 & 0 & 0 & -2 & 3 & 0 & -7 & N/A & 0 & 3 & A & \\
\hline $85 / 1$ & Sheep & Cotyledon & Kalavryta & 2014 & 29.9 & 0 & 0 & 0 & -2 & 3 & 0 & -7 & N/A & 0 & 3 & A & \\
\hline $85 / 1$ & Sheep & Stomach content & Kalavryta & 2014 & 27.4 & 0 & 0 & 0 & -2 & 3 & 0 & -7 & N/A & 0 & 3 & A & \\
\hline 92 & Sheep & Liver & Edessa & 2015 & 28.3 & 0 & 0 & 0 & -2 & 3 & 0 & -7 & N/A & 0 & 3 & $A$ & \\
\hline 113 & Sheep & Stomach content & Thessalonika & 2015 & 23.5 & 0 & 0 & 0 & -2 & 3 & 0 & -4 & N/A & 0 & 3 & B & 32 \\
\hline $152 / 2$ & Sheep & Cotyledon & Patra & 2016 & 29.1 & 0 & 0 & 0 & -2 & 3 & 0 & -7 & N/A & 0 & 3 & A & \\
\hline 156/B & Sheep & Stomach content & Aridea & 2016 & 28.4 & 0 & 0 & 0 & -2 & 3 & 0 & -7 & N/A & 0 & 3 & A & \\
\hline 173 & Sheep & Liver & Elassona & 2016 & 24.6 & 0 & 0 & 0 & -2 & 3 & 0 & -7 & N/A & 0 & 3 & A & 32 \\
\hline 173 & Sheep & Stomach content & Elassona & 2016 & 23.7 & 0 & 0 & 0 & -2 & 3 & 0 & -7 & N/A & 0 & 3 & A & 32 \\
\hline $14 / 1$ & Sheep & Cotyledon & Larissa & 2017 & 24.2 & 0 & 0 & 0 & -2 & 3 & 0 & 1 & N/A & -1 & 9 & C & 32 \\
\hline
\end{tabular}

ID Sample Identification number, Ct Real-time PCR cycle threshold, N/A not determined DNA. The genotypic designation of Nine Mile (4-7-8-8-15-6-6-4-12-4, for the corresponding loci) was used to compare our findings. Where " 0 ", we ended up with the same band size during the MLVA typing; differences either these are "-" or " $+"$ correspond to differences in number of repeats among our samples and Nine Mile. MLVA and MST genotypes were confirmed in C. burnetii 2014 cooperative database (http://mlva.u-psud.fr/mlvav4/genotyping/view.php) (http://ifr48.timone.univ-mrs.fr/mst/coxiella_burnetii/strains.html)

dominant occurring in different areas of the country, some separated by hundreds of kilometers. This large distribution may be due to the movement of animals from one place to another, or to a common animal supplier (who does not necessarily have to be Greek). Since only sheep samples have been genotyped, it can also be claimed that $C$. burnetii strains circulating in this animal population in Greece are very similar and more/other MLVA loci may be need to increase the discriminatory power. For example, we have failed to amplify the locus $m s 26$ independently from the specimen and the qPCR $\mathrm{Ct}$ values; the reason for this depletion has already been explained in a recent study [32] according to which, the loss of $m s 26$ is due to a deletion occurring between CBU_0877 and CBU_0881.

The genotypes identified in the current studied were designated as novel ones since no correspondence was found among the loci repeats profiles detected herein and those identified in other European studies, which have been deposited at the open web-site http:// mlva.u-psud.fr/MLVAnet/spip.php?rubrique50. Interestingly, the representatives of each of these three MLVA genotypes were found to be identical based on the 10- spacers MST panel and were identified as belonging to MST 32 group when the spacer's profile was compared with those deposited at http://ifr48.timone.univ-mrs.fr/mst/coxiella_burnetii/strains.html. Up to now the information regarding $C$. burnetii diversity in Greece was restricted to the description of Heizenberg str from an human sample, a strain close related to MST 18 [11]. This study increased the number of $C$. burnetii strains with zoonotic potential which are associated to small ruminants and circulate in the Hellenic territory. MST 32 was previously recorded in human specimens, heart valve (Germany) and aortic biopsy (France), in a goat placenta (Austria) and sheep soft cheese (Italy) [11, 24].

The increased use of molecular methods for epidemiological purposes has proven to be of great value both in the identification of animals seeding $C$. burnetii and tracking-back the disease, especially when accompanied by typing schemes. Since the first proposition of a panel to be used for the genotyping of C. burnetii [10, 11], a number of studies have been carried out throughout Europe to increase knowledge on the circulating strains. Effort has been made to genotype as many positive samples as possible and to expand the panel used, introducing more loci to increase strain identification. The main focus has been put into MLVA and MST. In fact is has been suggested that MLVA presents the highest discriminatory power [33], while different techniques seem to agree among each other [34, 35]. The great advantage of both methods (but of MLVA in particular) is that they do not require the isolation of the pathogen $[10,11]$. Genomic analyses can be made using directly the DNA purified from most type of samples, although results are best achieved if high bacterial load is present, as in the case of aborted material. Furthermore, typing by MLVA can be easily standardized since it has become pretty much straightforward and can be performed without the need of a large budget, and may prove of great usefulness in case of large-scale molecular epidemiology investigations [10]. It has, also, been shown that the selected MLVA markers are of high quality and show considerable stability [36], which is of particulate importance since regions that evolve too 
rapidly may prove misleading during an epidemiological surveillance [37].

A point of concern regarding MLVA is the presence of PCR products of unexpected size and/or failures to amplify certain loci, an aspect for which little has been discussed. For instance, a study carried out recently has shown that locus ms36 contains the full sequence of locus ms20. Thus, it may be possible that primers targeting ms36 may well amplify both loci resulting in a PCR product whose size may depend on the variations at the $9 \mathrm{bp}$ motif of ms36, the $18 \mathrm{bp}$ motif of ms 20 or at both [32]. Further attention is required when analyzing the results to avoid mis-calculations that may lead to erroneous comparisons with data of other studies [38, 39]. A step forward on this has been made through the recent introduction of the microfluidics technology on the field of MLVA typing. A recent study [40] showed that this technology proved to be more reliable and more sensitive when compared to standard electrophoretic techniques, which could add reproducibility, sensitivity and high fidelity to the procedure of typing, making the quality of the results produced being comparable to those of sequencing. Moreover, the lack of harmonization of the MLVA panels and of the loci amplified, allied with the high discriminatory power is leading to results that are difficult to compare among each other [21, 41], which in turn makes sometimes inter-laboratory comparison of results difficult. Thus, it is advantageous to associate MLVA with another typing method, such as MST [36]. As shown here, the selection of this latter method that is less discriminatory and uses standardized nomenclature enables the integration of the results obtained in this study. Adding to the above the use of plasmid characterization in addition to MLVA and MST typing has, also, been proposed [35]. Such an approach may help towards the better deepening on the elucidation of the source of some of the already described genotypes.

In any case, human isolates need to be tested [an attempt towards this direction has already been made by a research group in Hungary [42] using similar techniques in an attempt to identify the genotypes causing disease in humans, their virulence, the different symptoms or their duration that may cause, etc. At the same time, a number of issues need to be resolved when working with human samples, since the human blood may contain much lower DNA concentration compared to animal samples (abortion materials, swabs, etc). In fact, in a study carried out in Croatia [38] the authors failed to amplify by MLVA any of the samples that came out positive by conventional PCR and they attributed this finding to low DNA concentration [7].

To establish the link between the source of C. burnetii and a disease case or an outbreak it is crucial to obtain the proper sample. Under this context, abortion material may prove valuable providing information on the genotypic diversity but it constitutes only one approach to tracking-back the C. burnetii source. Environmental samples such as surface swabs and aerosols may, also, prove of particular interest [43]. In fact, contaminated aerosols are considered as one of the most important transmission routes for C. burnetii, especially when the environmental conditions favor dispersal by aerosol means $[6,44]$. Actually, it has been proven that large quantities $\left(>3 \times 10^{7} \mathrm{GE}\right.$ per gram of feces or $10^{3}$ GE per swab) of the pathogen may remain in faeces and vaginal mucus for more than 2 months [45]. Female ruminants that may suffer from abotrions, also called "superspreaders" [46], release large bacterial burdens into the environment; this aspect together with the viability of the pathogen in litter and manure infected by birth products, makes the need for testing other materials as well, more than necessary. It has, also, been suggested that typing of C. burnetii genotypes associated with the wildlife may prove of great importance towards the identification of a potential epidemiological link between wildlife and human and/ or livestock cases [47].

In Greece there are no past data because of the absence of any isolates from ruminants over the past decades. Therefore, the current survey constitutes the first attempt to genotype C. burnetii strains in Greece. Certainly much more work needs to be done and many more samples need to be tested in order to record as many different genotypes as possible, as well as, to cover most of the country territory. Furthermore, there is certainly a need to compare strains from abortion animals against those of healthy ones. The collection of such data and their comparison with data deposited in international databases will help towards both the continuing of the active surveillance and strain genotyping of the pathogen, as well as, to the better understanding of the epidemiology of the disease across Europe.

\section{Conclusion}

Genotyping of $C$. burnetii in a region is critical when trying to identify the major sources of infection, and to implement efficient farm-based control measures. MLVA analysis has been proven as a great molecular tool, the great advantage of which is that it does not require the isolation of the pathogen.

This is the first report of genotypic diversity among $C$. burnetii strains from Greece. Despite the low number of positive samples tested in our study, we have tried to make the first step on the introduction of genotyping of C. burnetii in the country. Certainly, there is much more 
to do in terms of animal surveillance and of human isolates that need to be genotyped, as well.

\section{Additional file}

Additional file 1: Table S1. List of data from studies that have been already carried out in Europe on the aspect C. burnetii genotyping. These data were used to build Fig. 2. The corresponding references of the studies are also provided at a separate tab into the file. (XLSX $50 \mathrm{~kb}$ )

\section{Abbreviations}

BSL: Biosafety Level; MLVA: Multi-locus variable number of tandem repeats analysis; MST: Multispacer sequence typing; PFGE: Pulse field gel electrophoresis: RFLP: Restriction fragment length polymorphism; SNP: Single nucleotide polymorphism

\section{Acknowledgements}

This work was performed under the frame of EurNegVec Cost Action TD1303.

\section{Funding}

None.

\section{Availability of data and materials}

All data have been published at online databases (http://microbesgenotyping. i2bc.paris-saclay.fr/databases/public), or are presented as supplementary material or are available if requested.

\section{Authors' contributions}

DC did the analysis of the samples and contributed on the writing of the manuscript. ASS did the analysis of the samples and contributed on the editing of the manuscript. NDG contributed on the collection of the samples, on the supervision of the study and on the editing of the manuscript. DP did the DNA extractions and contributed on the writing of the manuscript. LB did the analysis of the samples. EK contributed on the collection of the samples contributed on the editing of the manuscript. AP supervised the laboratory procedures at the laboratory in Crete and contributed on the editing of the manuscript. SKK and EIP supervised the laboratory procedures at the laboratory in Thessaloniki and contributed on the editing of the manuscript. All authors read and approved the final manuscript.

\section{Ethics approval and consent to participate}

Not applicable.

\section{Consent for publication}

Not applicable.

\section{Competing interests}

The authors declare that they have no competing interests.

\section{Publisher's Note}

Springer Nature remains neutral with regard to jurisdictional claims in published maps and institutional affiliations.

\section{Author details}

${ }^{1}$ Department of Clinical Microbiology and Microbial Pathogenesis, School of Medicine, University of Crete, Voutes-Staurakia, 71110 Heraklion, Crete, Greece. ${ }^{2}$ Centre for Vectors and Infectious Diseases Research, National Institute of Health Dr. Ricardo Jorge, Águas de Moura, Portugal. ${ }^{3} \mathrm{Clinic}$ of Farm Animals, Faculty of Veterinary Medicine, School of Health Sciences, Aristotle University of Thessaloniki, Thessaloniki, Greece. ${ }^{4}$ Laboratory of Microbiology and Infectious Diseases, Faculty of Veterinary Medicine, Schoo of Health Sciences, Aristotle University of Thessaloniki, Thessaloniki, Greece. ${ }^{5}$ Unit of Zoonoses, Laboratory of Clinical Microbiology and Microbial Pathogenesis, Faculty of Medicine, University of Crete, P.O. Box: 1393, 71110 Heraklion, Crete, Greece.
Received: 11 June 2018 Accepted: 22 November 2018

Published online: 04 December 2018

\section{References}

1. Angelakis E, Raoult D. Q Fever. Vet Microbiol. 2010;140(3-4):297-309.

2. Bildfell RJ, Thomson GW, Haines DM, McEwen BJ, Smart N. Coxiella burnetii infection is associated with placentitis in cases of bovine abortion. J Vet Diagn Investig. 2000;12(5):419-25.

3. Ho T, Htwe KK, Yamasaki N, Zhang GQ, Ogawa M, Yamaguchi T, Fukushi H, Hirai K. Isolation of Coxiella burnetii from dairy cattle and ticks, and some characteristics of the isolates in Japan. Microbiol Immunol. 1995; 39(9):663-71.

4. Moeller RB, Jr: Causes of caprine abortion: diagnostic assessment of 211 cases (1991-1998). J Vet Diagn Investig 2001, 13(3):265-270.

5. Tissot-Dupont H, Torres S, Nezri M, Raoult D. Hyperendemic focus of Q fever related to sheep and wind. Am J Epidemiol. 1999;150(1):67-74.

6. Tissot-Dupont H, Amadei MA, Nezri M, Raoult D. Wind in November, Q fever in December. Emerg Infect Dis. 2004;10(7):1264-9.

7. Roest HI, Tilburg JJ, van der Hoek W, Vellema P, van Zijderveld FG, Klaassen $\mathrm{CH}$, Raoult D. The Q fever epidemic in the Netherlands: history, onset, response and reflection. Epidemiol Infect. 2011;139(1):1-12.

8. Heinzen R, Stiegler GL, Whiting LL, Schmitt SA, Mallavia LP, Frazier ME. Use of pulsed field gel electrophoresis to differentiate Coxiella burnetii strains. Ann N Y Acad Sci. 1990:590:504-13.

9. Jager C, Willems H, Thiele D, Baljer G. Molecular characterization of Coxiella burnetii isolates. Epidemiol Infect. 1998:120(2):157-64.

10. Arricau-Bouvery N, Hauck Y, Bejaoui A, Frangoulidis D, Bodier CC, Souriau A, Meyer $\mathrm{H}$, Neubauer H, Rodolakis A, Vergnaud G. Molecular characterization of Coxiella burnetii isolates by infrequent restriction site-PCR and MLVA typing. BMC Microbiol. 2006;6:38

11. Glazunova O, Roux V, Freylikman O, Sekeyova Z, Fournous G, Tyczka J, Tokarevich N, Kovacava E, Marrie TJ, Raoult D. Coxiella burnetii genotyping. Emerg Infect Dis. 2005:11(8):1211-7.

12. Hornstra HM, Priestley RA, Georgia SM, Kachur S, Birdsell DN, Hilsabeck R, Gates LT, Samuel JE, Heinzen RA, Kersh GJ, et al. Rapid typing of Coxiella burnetii. PLoS One. 2011;6(11):e26201.

13. Huijsmans CJ, Schellekens JJ, Wever PC, Toman R, Savelkoul PH, Janse I, Hermans MH. Single-nucleotide-polymorphism genotyping of Coxiella burnetii during a Q fever outbreak in the Netherlands. Appl Environ Microbiol. 2011;77(6):2051-7.

14. Le Fleche P, Fabre M, Denoeud F, Koeck JL, Vergnaud G. High resolution, on-line identification of strains from the Mycobacterium tuberculosis complex based on tandem repeat typing. BMC Microbiol. 2002;2:37.

15. Le Fleche $P$, Hauck $Y$, Onteniente L, Prieur A, Denoeud F, Ramisse $V$, Sylvestre $P$, Benson $G$, Ramisse F, Vergnaud $G$. A tandem repeats database for bacterial genomes: application to the genotyping of Yersinia pestis and bacillus anthracis. BMC Microbiol. 2001;1:2.

16. Pourcel C, Andre-Mazeaud F, Neubauer H, Ramisse F, Vergnaud G. Tandem repeats analysis for the high resolution phylogenetic analysis of Yersinia pestis. BMC Microbiol. 2004:4:22

17. Koeck UL, Njanpop-Lafourcade BM, Cade S, Varon E, Sangare L, Valjevac S, Vergnaud G, Pourcel C. Evaluation and selection of tandem repeat loci for Streptococcus pneumoniae MLVA strain typing. BMC Microbiol. 2005;5:66.

18. Le Fleche P, Jacques I, Grayon M, Al Dahouk S, Bouchon P, Denoeud F, Nockler K, Neubauer $H$, Guilloteau LA, Vergnaud G. Evaluation and selection of tandem repeat loci for a Brucella MLVA typing assay. BMC Microbiol. 2006;6:9.

19. Klee SR, Tyczka J, Ellerbrok H, Franz T, Linke S, Baljer G, Appel B. Highly sensitive real-time PCR for specific detection and quantification of Coxiella burnetii. BMC Microbiol. 2006;6:2.

20. Tilburg JJ, Melchers WJ, Pettersson AM, Rossen JW, Hermans MH, van Hannen EJ, Nabuurs-Franssen MH, de Vries MC, Horrevorts AM, Klaassen CH. Interlaboratory evaluation of different extraction and real-time PCR methods for detection of Coxiella burnetii DNA in serum. J Clin Microbiol. 2010; 48(11):3923-7.

21. Svraka S, Toman R, Skultety L, Slaba K, Homan WL. Establishment of a genotyping scheme for Coxiella burnetii. FEMS Microbiol Lett. 2006; 254(2):268-74

22. Tilburg JJ, Roest HJ, Buffet S, Nabuurs-Franssen MH, Horrevorts AM, Raoult D. Klaassen $\mathrm{CH}$. Epidemic genotype of Coxiella burnetii among goats, sheep, and humans in the Netherlands. Emerg Infect Dis. 2012;18(5):887-9. 
23. Kumar S, Stecher G, Tamura K. MEGA7: molecular evolutionary genetics analysis version 7.0 for bigger datasets. Mol Biol Evol. 2016;33(7):1870-4.

24. Galiero A, Fratini F, Camma C, Di Domenico M, Curini V, Baronti I, Turchi B, Cerri D. Occurrence of Coxiella burnetii in goat and ewe unpasteurized cheeses: screening and genotyping. Int J Food Microbiol. 2016;237:47-54.

25. Spyridaki I, Gikas A, Kofteridis D, Psaroulaki A, Tselentis Y. Q fever in the Greek island of Crete: detection, isolation, and molecular identification of eight strains of Coxiella burnetii from clinical samples. J Clin Microbiol. 1998;36(7):2063-7.

26. Kokkini S, Chochlakis D, Vranakis I, Angelakis E, Tselentis Y, Gikas A, Psaroulaki A. Antibody kinetics in serological indication of chronic Q fever: the Greek experience. Int J Infect Dis. 2013;17(11):e977-80.

27. Psaroulaki A, Ragiadakou D, Kouris G, Papadopoulos B, Chaniotis B, Tselentis Y. Ticks, tick-borne rickettsiae, and Coxiella burnetii in the Greek Island of Cephalonia. Ann N Y Acad Sci. 2006;1078:389-99.

28. Vranakis I, Sandalakis V, Chochlakis D, Tselentis Y, Psaroulaki A. DNA gyrase and topoisomerase IV mutations in an in vitro fluoroquinolone-resistant Coxiella burnetii strain. Microb Drug Resist. 2010;16(2):111-7.

29. Papadioti A, Markoutsa S, Vranakis I, Tselentis Y, Karas M, Psaroulaki A, Tsiotis G. A proteomic approach to investigate the differential antigenic profile of two Coxiella burnetii strains. J Proteome. 2011;74(7):1150-9.

30. Vranakis I, De Bock PJ, Papadioti A, Samoilis G, Tselentis Y, Gevaert K, Tsiotis G, Psaroulaki A. Unraveling persistent host cell infection with Coxiella burnetii by quantitative proteomics. J Proteome Res. 2011;10(9):4241-51.

31. Vranakis I, De Bock PJ, Papadioti A, Tselentis Y, Gevaert K, Tsiotis G, Psaroulaki A. Quantitative proteome profiling of C. burnetii under tetracycline stress conditions. PLoS One. 2012;7(3):e33599.

32. Sidi-Boumedine K, Duquesne V, Prigent M, Yang E, Joulie A, Thiery R, Rousset E. Impact of IS1111 insertion on the MLVA genotyping of Coxiella burnetii. Microbes Infect. 2015;17:789-94.

33. Tilburg JJ. Molecular investigation of the $\mathrm{Q}$ fever epidemic in the Netherlands. The largest outbreak caused by Coxiella burnetii ever reported. PhD Thesis. Boxpress, Nijmegen: Radboud Universiteit Nijmegen; 2013.

34. Astobiza I, Tilburg JJ, Pinero A, Hurtado A, Garcia-Perez AL, NabuursFranssen $\mathrm{MH}$, Klaassen $\mathrm{CH}$. Genotyping of Coxiella burnetii from do1112 mestic ruminants in northern Spain. BMC Vet Res. 2012;8:241.

35. Santos AS, Tilburg JJ, Botelho A, Barahona MJ, Nuncio MS, Nabuurs-Franssen $\mathrm{MH}$, Klaassen $\mathrm{CH}$. Genotypic diversity of clinical Coxiella burnetii isolates from Portugal based on MST and MLVA typing. Int J Med Microbiol. 2012; 302(6):253-6.

36. van Belkum A. Tracing isolates of bacterial species by multilocus variable number of tandem repeat analysis (MLVA). FEMS Immunol Med Microbiol. 2007:49(1):22-7.

37. Frangoulidis D, Walter MC, Antwerpen M, Zimmermann P, Janowetz B, Alex M, Bottcher J, Henning K, Hilbert A, Ganter M, et al. Molecular analysis of Coxiella burnetii in Germany reveals evolution of unique clonal clusters. Int J Med Microbiol. 2014;304(7):868-76.

38. Racic I, Spicic S, Galov A, Duvnjak S, Zdelar-Tuk M, Vujnovic A, Habrun B, Cvetnic Z. Identification of Coxiella burnetii genotypes in Croatia using multi-locus VNTR analysis. Vet Microbiol. 2014;173(3-4):340-7.

39. Roest HI, Ruuls RC, Tilburg JJ, Nabuurs-Franssen MH, Klaassen CH, Vellema P, van den Brom R, Dercksen D, Wouda W, Spierenburg MA, et al. Molecular epidemiology of Coxiella burnetii from ruminants in $\mathrm{Q}$ fever outbreak, the Netherlands. Emerg Infect Dis. 2011;17(4):668-75.

40. Prigent $M$, Rousset $E$, Yang E, Thiery R, Sidi-Boumedine K. Validation study for using lab-on-chip technology for Coxiella burnetii multi-locus-VNTR-analysis (MLVA) typing: application for studying genotypic diversity of strains from domestic ruminants in France. Microbes Infect. 2015;17(11-12):782-8.

41. Koh XP, Chiou CS, Ajam N, Watanabe H, Ahmad N, Thong KL. Characterization of Shigella sonnei in Malaysia, an increasingly prevalent etiologic agent of local shigellosis cases. BMC Infect Dis. 2012;12:122.

42. Sulyok KM, Kreizinger Z, Hornstra HM, Pearson T, Szigeti A, Dan A, Balla E, Keim PS, Gyuranecz M. Genotyping of Coxiella burnetii from domestic ruminants and human in Hungary: indication of various genotypes. BMC Vet Res. 2014;10:107.

43. de Bruin $A$, van Alphen $P T$, van der Plaats $R Q$, de Heer $L N$, Reusken $C B$, van Rotterdam BJ, Janse I. Molecular typing of Coxiella burnetii from animal and environmental matrices during Q fever epidemics in the Netherlands. BMC Vet Res. 2012;8:165.
44. van der Hoek W, Hunink J, Vellema P, Droogers P. Q fever in the Netherlands: the role of local environmental conditions. Int J Environ Health Res. 2011;21(6):441-51

45. Joulie A, Laroucau K, Bailly X, Prigent M, Gasqui P, Lepetitcolin E, Blanchard $B$, Rousset E, Sidi-Boumedine K, Jourdain E. Circulation of Coxiella burnetii in a naturally infected flock of dairy sheep: shedding dynamics, environmental contamination, and genotype diversity. Appl Environ Microbiol. 2015; 81(20):7253-60

46. Porten K, Rissland J, Tigges A, Broll S, Hopp W, Lunemann M, van Treeck U, Kimmig P, Brockmann SO, Wagner-Wiening C, et al. A super-spreading ewe infects hundreds with Q fever at a farmers' market in Germany. BMC Infect Dis. 2006;6:147.

47. Pinero A, Ruiz-Fons F, Hurtado A, Barandika JF, Atxaerandio R, Garcia-Perez AL. Changes in the dynamics of Coxiella burnetii infection in dairy cattle: an approach to match field data with the epidemiological cycle of $C$. burnetii in endemic herds. J Dairy Sci. 2014;97(5):2718-30.

\section{Ready to submit your research? Choose BMC and benefit from:}

- fast, convenient online submission

- thorough peer review by experienced researchers in your field

- rapid publication on acceptance

- support for research data, including large and complex data types

- gold Open Access which fosters wider collaboration and increased citations

- maximum visibility for your research: over $100 \mathrm{M}$ website views per year

At BMC, research is always in progress.

Learn more biomedcentral.com/submissions 